\title{
Use of Halophilic Bacteria to Improve Aerobic Granular Sludge Integrity in Hypersaline Wastewaters
}

\author{
Abdullah Ibrahim, ${ }^{1,2}$ Yasawantha Hiripitiyage, ${ }^{1}$ Edward Peltier,, ${ }^{1, *}$ and Belinda S.M. Sturm ${ }^{1, \dagger}$ \\ ${ }^{1}$ Department of Civil, Environmental, and Architectural Engineering, University of Kansas, Lawrence, Kansas. \\ ${ }^{2}$ Department of Environmental Engineering, University of Mosul, Mosul, Iraq.
}

Received: August 23, 2019 Accepted in revised form: January 19, 2020

\begin{abstract}
Aerobic granular sludge (AGS) reactors are often limited in their ability to treat high-salinity wastewaters. In this study, the performance of an AGS reactor inoculated with an enriched halophilic culture was compared with one seeded with activated sludge at salt concentrations ranging from $<1$ to $85 \mathrm{~g} \mathrm{NaCl} / \mathrm{L}$. While the activated sludge-inoculated reactor initially formed larger granules, the halophile-inoculated reactor better retained granule structure at hypersaline conditions $(>40 \mathrm{~g} \mathrm{NaCl} / \mathrm{L})$, with average granule diameters between 0.8 and $1 \mathrm{~mm}$, approximately double the size of those in the activated sludge reactor. The halophilic reactor also produced significantly higher amounts of both total extracellular polymeric substances (EPS) and alginate-like exopolysaccharides under hypersaline conditions. The halophilic inoculum also retained lower concentrations of intracellular $\mathrm{Na}^{+}(100 \mathrm{mg} / \mathrm{g}$ mixed liquor volatile suspended solids [MLVSS] vs. $125 \mathrm{mg} / \mathrm{g}$ MLVSS in the activated sludge reactor) at $85 \mathrm{~g} / \mathrm{L} \mathrm{NaCl}$. In contrast, both cultures exhibited the same behavior with respect to $\mathrm{Na}^{+}$substitution for divalent cations in extracted EPS. Illumina 16S targeted gene sequencing data analysis showed that the population of both reactors converged toward halophile-dominated systems, primarily by bacteria belonging to the phyla Proteobacteria and Bacteroidetes, at hypersaline conditions. This represented a substantial decrease in diversity for the activated sludge reactor compared with the initial inoculum, but a slight increase for the halophile-inoculated reactor. Despite the similarity in community structure, the differences in granule formation and stability indicate that adding halophilic organisms in the initial inoculum produces better granules under hypersaline conditions.
\end{abstract}

Keywords: aerobic granular sludge; alginate-like exopolysaccharides; extracellular polymeric substance; hypersaline produced water; microbial community shifting

\section{Introduction}

$\mathbf{H}$ IGH-SALINITY WASTEWATERS from industries (tanning, food processing, oil and gas production) and coastal communities present special challenges for biological treatment, as conventional activated sludge processes have limited ability to perform in these harsh environments (Lefebvre and Moletta, 2006; Salminikhas et al., 2016; Corsino et al., 2018). Aerobic granular sludge (AGS) is a biofilm technology that has seen rapid growth for municipal and industrial wastewater treatment within the last decade (Fakhru'l-Razi et al., 2009; Pronk et al., 2014). The formation of granules improves the settleability of the microbial biomass, while also improving its ability to withstand shocks due to fluctuations in wastewater composition and protecting slower

*Corresponding author: Department of Civil, Environmental, and Architectural Engineering, University of Kansas, 1530 West 15th Street, Lawrence, KS 66045, USA. Phone: 785-864-2941; Fax: 785-864-5631; E-mail: epeltier@ku.edu

${ }^{\dagger}$ Member of AEESP. growing microorganisms from high pollutant concentrations (Gao et al., 2011; Taheri et al., 2012). These properties make AGS a promising technology for treating industrial wastewaters. However, maintaining the structure of aerobic sludge granules becomes more difficult as the salinity increases. Multiple studies using bacteria derived from domestic wastewater treatment and related sources have noted severe degradation in granule structure and activity as salt concentrations reach 20-50 g/L (Taheri et al., 2012; Pronk et al., 2014; Ramos et al., 2015; Corsino et al., 2017; Wang et al., 2017a). Some success has been reported using individual salt-tolerant microorganisms to treat high-salinity wastewaters (Abou-Elela et al., 2010; Castillo-Carvajal et al., 2014), but these systems are often sensitive to disruptions resulting from changes in wastewater composition (Cui et al., 2016). More recently, Huang et al. (2019) successfully used a mixture of salt-tolerant and halophilic species obtained from estuarine sediments to develop halophilic granules to remove ammonia and chemical oxygen demand (COD) from wastewater at $30 \mathrm{~g} / \mathrm{L}$ salinity. 
A key component to granular stability is the production of extracellular polymeric substances (EPS), which bind organisms together and help protect cells from environmental conditions (Capodici et al., 2015; Deng et al., 2016). Salt stress can result in changes in the quantity and quality of EPS production in AGS systems (Taheri et al., 2012; Corsino et al., 2017; Wang et al., 2017a). For example, Corsino et al. (2017) observed increases in the fraction of "not-bound" EPS and a reduction in EPS protein content above $50 \mathrm{~g} / \mathrm{L}$ $\mathrm{NaCl}$. Alginate-like exopolysaccharides (ALE) predominantly comprised both mannuronic and guluronic acids ( $\mathrm{Li}$ et al., 2017) and are classified as one of the most abundant exopolysaccharides in AGS (Lin et al., 2013). It has been reported that the presence of ALE can increase AGS stability because it has strong mechanical properties and a high affinity for some divalent cations, such as $\mathrm{Ca}^{2+}$ and $\mathrm{Mg}^{2+}$. In addition, ALE have the ability to embed some components, such as proteins and lipids, which enhance AGS aggregation (Lin et al., 2010; Li et al., 2017).

High concentrations of aqueous sodium, which occur in most high-salinity wastewaters, can impact both individual organism viability and AGS stability. It has been suggested that divalent cations, primarily $\mathrm{Ca}^{2+}$ and $\mathrm{Mg}^{2+}$, play an important role in bioflocculation by bridging negatively charged sites on cell surfaces and by binding biopolymers to each other (Kara et al., 2008). Substitution of monovalent $\mathrm{Na}^{+}$and $\mathrm{K}^{+}$for divalent cations in the EPS matrix has been shown to negatively impact granule formation and activated sludge settleability (Higgins and Novak, 1997; Li and Yang, 2007; Ismail et al., 2010; Fang et al., 2018).

More recently, investigators have developed AGS systems with some tolerance for high-salinity wastewaters (Bassin et al., 2011; Taheri et al., 2012; Pronk et al., 2014). Ou et al. (2018) investigated the effect of $0-9 \% \mathrm{w} / \mathrm{v} \mathrm{NaCl}$ on AGS formation and the bacterial community in laboratory-scale reactors. As the salt content increased to $9 \%$, halophilic bacteria became abundant in the reactors. However, removal efficiency (as COD) declined to $50 \%$ at $9 \%$ salt content. In addition, Wang et al. (2017b) studied adaption strategies to reduce the effect of salinity on AGS formation and nutrient removal, with higher levels of dissolved oxygen improving AGS formation as the $\mathrm{NaCl}$ content increased to $15 \mathrm{~g} / \mathrm{L}$. Li et al. (2017) studied AGS granulation in mixtures of saline synthetic sewage with seawater, and observed stronger granular structure, with more ALE production, as the salinity increased due to higher seawater content. This result was attributed to the difference between real seawater and synthetic salt solutions, particularly the presence of a wider range of metal cations. While studies of AGS systems using halophilic bacteria are rare, Huang et al. (2019) used selective settling pressure to form aerobic halophilic granules in a sequencing batch reactor (SBR) at a salt concentration of $30 \mathrm{~g} / \mathrm{L}$. EPS production was observed to increase with higher organic loading rates. The protein content of EPS was correlated with increasing granule size, while ALE was found only in mature granules.

Based on these results, the use of AGS for remediation of high-salinity wastewaters may be improved using halophilic organisms that are adapted to function in these environments. This study investigates the effectiveness of bioaugmentation with a halophilic bacteria culture on the development of stable aerobic granules under hypersaline conditions. Two SBRs were operated —one with activated sludge and one with an enriched halophilic community as the inoculum. Granule size, integrity, and composition (including EPS and ALE production and divalent cation content) were examined in both systems as salt concentrations gradually increased from $<1$ to $85 \mathrm{~g} / \mathrm{L}$ to provide insight on adaptations that improve granule stability under high-salinity conditions. Insight on reactor community changes was provided through $16 \mathrm{~S}$ targeted gene sequencing of the samples obtained during hypersaline operation.

\section{Materials and Methods}

\section{Experimental setup and operation conditions}

Two identical 3.0 L bench-scale SBRs were operated with an internal diameter of $6.5 \mathrm{~cm}$ and an effective height of $88.5 \mathrm{~cm}$; the volumetric exchange ratio was $50 \%$. The superficial upflow air velocity was maintained at $1.1 \mathrm{~cm} / \mathrm{s}$. Initially, reactors were operated with a 6-h cycle that comprised four phases: 30-min anaerobic feeding through the settled sludge bed, 315-min aeration, 10-min settling, and 5-min decanting. Fine bioflocs started to appear in both reactors after 14 days of operation, with stable granules (diameter $>0.2 \mathrm{~mm}$ ) appearing after 37 days of operation. At this point, settling time was gradually reduced to $3 \mathrm{~min}$ and the aeration time increased to 322 min over a 20-day period. These time parameters were then used throughout the experiment. Once mature granules appeared (after 37 days of operation), the sodium chloride content was increased stepwise over time from $<1$ to $85 \mathrm{~g}$ $\mathrm{NaCl} / \mathrm{L}$. After each increase in influent salt concentration, the reactors were maintained at that new concentration until the mixed liquor volatile suspended solid (MLVSS) concentration and COD removal stabilized, a process that typically took 7-10 days (Fig. 1). Once the reactor reached stable operation, the salt concentration was increased again. Throughout the experiment, sludge retention time in both reactors was maintained at $\sim 28-30$ days, depending on the mass of sludge withdrawn for measurements. The temperature was maintained at $21 \pm 1^{\circ} \mathrm{C}$, while the $\mathrm{pH}$ of the influent wastewater was adjusted to $7.2 \pm 0.1$ by addition of $1 \mathrm{M} \mathrm{HCl}$ or $1 \mathrm{M} \mathrm{NaOH}$.

A hypersaline feed solution (Table 1) was modified from previously published recipes for high-salinity oil and gas synthetic wastewater, or produced water (Pendashteh et al., 2012; Sharghi et al., 2014). The $\mathrm{C} / \mathrm{N} / \mathrm{P}$ ratio was adjusted to $\sim 100 / 10 / 1$ by adding $\mathrm{NH}_{4} \mathrm{Cl}$ and $\mathrm{KH}_{2} \mathrm{PO}_{4}$, and a trace element solution was added at $0.2 \mathrm{~mL} / \mathrm{L}$ of final solution ( $\mathrm{Li}$ et al., 2017). The $\mathrm{NaCl}$ content was increased stepwise over time from $<1$ to $85 \mathrm{~g} / \mathrm{L}$ using a commercially available salt compound, which our analysis confirmed to be 95-98\% pure $\mathrm{NaCl}$. Acetate was used as the sole carbon source with an organic load of $1,350 \mathrm{mg} \mathrm{COD} / \mathrm{L}$. For the first reactor, a halophilic biomass culture obtained from a previous experiment was grown in marine salt medium (ATCC medium no. 1487) for 15 days to select for halophilic organisms. Fifty milliliters of this material was then used to inoculate the reactor. The second reactor was inoculated with activated sludge collected from the aeration tank of a municipal wastewater treatment plant in Lawrence, KS.

\section{Analytical procedures}

Mixed liquor suspended solids (MLSS), MLVSS, and sludge volume index at $5 \mathrm{~min}\left(\mathrm{SVI}_{5}\right)$ were quantified based 
FIG. 1. MLVSS concentration for enriched halophilic and activated sludge culture along with study period. MLVSS, mixed liquor volatile suspended solids.

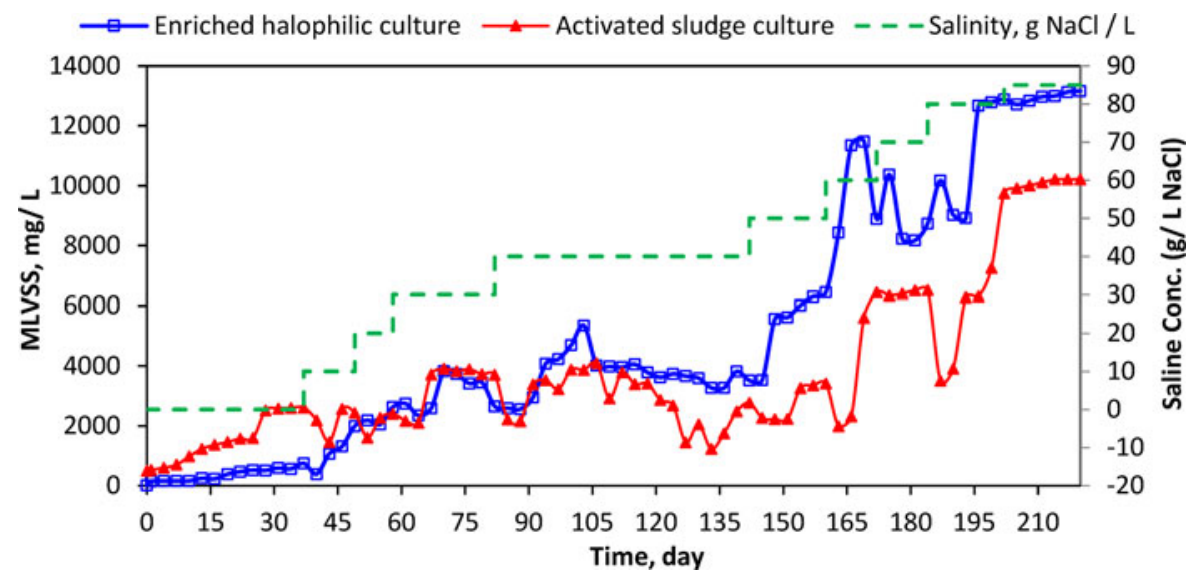

on standard methods (APHA, 2005). A stereomicroscope (Fisher Scientific) was used to capture granule images twice a week during the experiment. The average granule diameter and aspect ratio, defined here as the ratio of longitudinal to latitudinal diameter of the granular sludge particle, were analyzed using Fiji image software. Since the chloride content was elevated in these samples, COD was determined according to the method proposed by Vyrides and Stuckey (2009), which accounts for chloride interference.

Extraction of loosely bound EPS and tightly bound EPS (TB-EPS) was carried out using the heat method described by Li and Yang (2007), and quantified as COD. During the extraction process, samples were centrifuged twice, with the supernatant discarded each time and the biomass pellet resuspended into $30 \mathrm{~mL}$ of phosphatebuffered saline preheated at $60^{\circ} \mathrm{C}$. After a third centrifugation step, the biomass pellet remaining in the centrifuge tube after the TB-EPS extraction was stored and was later digested to determine intracellular cation concentrations. The ALE fraction of the EPS was isolated according to the method proposed by Felz et al. (2016) as the sodium form of ALE, then quantified by a phenol/ sulfuric acid assay using sodium alginate as a standard (Dubois et al., 1956). ALE extraction began only once both reactors had reached $40 \mathrm{~g} / \mathrm{L} \mathrm{NaCl}$, and was carried out throughout the hypersaline range.

A temperature-controlled microwave-assisted digestion procedure based on Özsoy (2006) was used to extract cations $\left(\mathrm{Ca}^{2+}, \mathrm{Mg}^{2+}, \mathrm{Na}^{+}, \mathrm{K}^{+}\right)$from EPS and biomass samples. Diluted samples of extracted EPS were mixed with $2 \mathrm{~mL}$ of nitric acid and $0.5 \mathrm{~mL}$ of hydrochloric acid to make a final volume of
$22.5 \mathrm{~mL}$. The solution was heated to $170^{\circ} \mathrm{C}$ over $10 \mathrm{~min}$ and then held at that temperature for an additional $10 \mathrm{~min}$, followed by $17 \mathrm{~min}$ of heating at $70^{\circ} \mathrm{C}$. For intracellular cation analysis, about $0.35 \pm 0.1 \mathrm{~g}$ of biomass left after TB-EPS extraction was mixed with $6 \mathrm{~mL}$ of nitric acid and $2 \mathrm{~mL}$ of hydrochloric acid, and then the same microwave-assisted digestion procedure was applied. Digested samples were diluted to $100 \mathrm{~mL}$ with deionized water, filtered through a $0.45 \mu \mathrm{m}$ filter, and then analyzed by inductively coupled plasma-optical emission spectrometry (PerkinElmer; Optima 2000 DV) to determine $\mathrm{Ca}^{2+}, \mathrm{Mg}^{2+}, \mathrm{K}^{+}$, and $\mathrm{Na}^{+}$concentrations.

\section{Microbial community analysis}

DNA was extracted from duplicate mixed liquor samples collected at inoculation and at every stepwise increase in $\mathrm{NaCl}$ concentration from $40 \mathrm{~g} / \mathrm{L}$ on in both reactors. The extracted DNA was used to generate amplicons with primers targeting the V4 hypervariable region of the 16S rRNA gene (Caporaso et al., 2011). Illumina NGS libraries were prepared from the amplicons and finally sequenced on an Illumina MiSeq sequencer at the Integrated Genomic Facility at Kansas State University, Manhattan, KS. A detailed description of the DNA extraction, amplicon generation, and Illumina library preparation is available in the Supplementary Data.

\section{Sequence data analysis}

Illumina sequence data were analyzed by the Center for Microbial Metagenomic Community Analysis at the University of Kansas, Lawrence, KS. The raw reads were filtered

Table 1. Composition of Reactor Feed Solution, Including Trace Elements

\begin{tabular}{|c|c|c|c|}
\hline Compound & Concentration (mM) & Compound & Concentration $(\mu M)$ \\
\hline $\mathrm{NaCl}$ & $0-1,283$ & $\mathrm{FeCl}_{3} \cdot 6 \mathrm{H}_{2} \mathrm{O}$ & 11.1 \\
\hline $\mathrm{CaCl}_{2} \cdot 2 \mathrm{H}_{2} \mathrm{O}$ & 0.41 & $\mathrm{H}_{3} \mathrm{BO}_{3}$ & 4.85 \\
\hline $\mathrm{KCl}$ & 26.8 & $\mathrm{CuSO}_{4} \cdot 5 \mathrm{H}_{2} \mathrm{O}$ & 0.24 \\
\hline $\mathrm{MgCl}_{2} \cdot 6 \mathrm{H}_{2} \mathrm{O}$ & 0.25 & $\mathrm{KI}$ & 0.36 \\
\hline $\mathrm{NaHCO}_{3}$ & 9.52 & $\mathrm{MnCl}_{2} \cdot 4 \mathrm{H}_{2} \mathrm{O}$ & 1.21 \\
\hline $\mathrm{NH}_{4} \mathrm{Cl}$ & 16.1 & $\mathrm{Na}_{2} \mathrm{MoO}_{4} \cdot 2 \mathrm{H}_{2} \mathrm{O}$ & 0.50 \\
\hline $\mathrm{KH}_{2} \mathrm{PO}_{4}$ & 0.73 & $\mathrm{ZnSO}_{4} \cdot 7 \mathrm{H}_{2} \mathrm{O}$ & 0.83 \\
\hline $\mathrm{Mg} \mathrm{SO}_{4}$ & 4.15 & $\mathrm{CoCl}_{2} \cdot 6 \mathrm{H}_{2} \mathrm{O}$ & 1.26 \\
\hline $\mathrm{NaCH}_{3} \mathrm{COO}$ & 39.0 & & \\
\hline
\end{tabular}


for quality and sorted into operational taxonomic units using the Quantitative Insights into Microbial Ecology2 software suite (QIIME2 v2017.12) (Caporaso et al., 2010).

\section{Statistical analysis}

Duplicate samples were taken for all measurements. All plots of reactor data show mean values for the relevant data, with error bars representing two standard deviations from this mean. Differences in mean values between reactors or between different operating conditions were analyzed for statistical significance using a two-sample Student's $t$-test at 95\% confidence ( $p$ value $\leq 0.05$ ). $t$-Test and Pearson's correlation analysis were performed using Minitab 17 (Minitab 17 Statistical Software, 2010). R version 3.4 (R Core Team) was used to run statistical analysis related to microbiome community data.

\section{Results}

MLVSS concentrations in the halophilic reactor were initially lower than in the activated sludge reactor, but reached comparable levels at $20 \mathrm{~g} / \mathrm{L} \mathrm{NaCl}$ (Fig. 1). Above $40 \mathrm{~g} / \mathrm{L}$, the halophilic reactor MLVSS continued to increase, and was consistently between 10,000 and $13,000 \mathrm{mg} / \mathrm{L}$ by the end of the study, with MLVSS/MLSS ratios around 0.78. By contrast, the biomass content in the activated sludge reactor dropped to below $4,000 \mathrm{mg} / \mathrm{L}$ when the salt concentration was increased to $40 \mathrm{~g} / \mathrm{L} \mathrm{NaCl}$. Under hypersaline conditions, activated sludge reactor biomass was always lower than that in the enriched halophile reactor, although concentrations did begin to increase again after 165 days $(70 \mathrm{~g} / \mathrm{L} \mathrm{NaCl})$. MLVSS/MLSS ratios were similar in both reactors, at $0.76-0.78$. COD removal was initially lower in the enriched halophile reactor, possibly due to the low-salinity environment, but increased as $\mathrm{NaCl}$ was added, and remained above $90 \%$ under hypersaline conditions (Supplementary Table S1). COD removal in the activated sludge reactor varied between $80 \%$ and $90 \%$ throughout the experiment. Although the reactors had different solid contents, statistical analysis showed no significant differences $(p>0.05)$ in $\mathrm{SVI}_{5}$ between reactors.

\section{AGS formation}

Granule sizes in both reactors were very similar during the start-up period (Fig. 2). The average granule diameter in the activated sludge reactor was higher during the lower salinity stage $(10-40 \mathrm{~g} / \mathrm{L})$. This better granulation corresponded with a dark yellow appearance and a solid smooth surface (Fig. 3). By contrast, the halophile-inoculated granules had a light-yellow appearance and a rougher granule surface. Under hypersaline conditions ( $40-85 \mathrm{~g} / \mathrm{L})$, the average granule size in the activated sludge reactor declined from $1.25 \pm 0.2 \mathrm{~mm}$ to $0.4 \pm 0.1 \mathrm{~mm}$ as salinity increased, and the aspect ratio decreased to 0.52 (Fig. 2). By contrast, the granule size in the halophilic reactor decreased only slightly (from $1.05 \pm 0.2 \mathrm{~mm}$ to $0.95 \pm 0.4 \mathrm{~mm}$ ) and maintained an aspect ratio of 0.60 . Statistical analysis showed that there was a significant difference $(p<0.05)$ between granule sizes in the two reactors during hypersaline operation $(\geq 40 \mathrm{~g} / \mathrm{L})$, but not during operation at lower salinity. At higher salinity levels, the external shape of the halophileinoculated granules also appeared more solid (Fig. 3).

\section{EPS production and composition}

EPS extracted at the end of the aeration cycle (measured as $\mathrm{mg}$ of COD) were normalized to MLVSS concentration (Fig. 4A). EPS production was relatively stable in the halophile-inoculated reactor, with a small decrease in production relative to total biomass at $80-85 \mathrm{~g} / \mathrm{L}$. In the activated sludge reactor, EPS production increased through the lowsalinity range, but decreased rapidly between 35 and $45 \mathrm{~g} / \mathrm{L}$ $\mathrm{NaCl}$. It then remained relatively consistent at $\sim 400 \mathrm{mg} / \mathrm{g}$ MLVSS throughout the hypersaline range. Tightly bound EPS accounted for approximately two-thirds of the total EPS, on average, in both reactors (Supplementary Figs. S1 and S2). No consistent impact of salinity on the relative amounts of tightly and loosely bound EPS was observed.

ALE concentrations under hypersaline conditions (40-85 g/L $\mathrm{NaCl}$ ) ranged from 81 to $161 \mathrm{mg} / \mathrm{g}$ MLVSS and $116-171 \mathrm{mg} / \mathrm{g}$ MLVSS in the activated sludge and halophilic reactor, respectively. These concentrations are in the upper range of reported ALE concentrations for aerobic granular reactors under saline conditions (Li et al., 2017; Wang et al., 2017b; Huang et al., 2019; Meng et al., 2019). ALE production in the activated sludge reactor was lower than in the halophilic reactor, except at the highest salinity, and showed greater fluctuations as salinity increased (Fig. 4B). The difference in mean ALE concentration across the hypersaline range (40-80 $\mathrm{g} \mathrm{NaCl} / \mathrm{L}$ ) between the two reactors was statistically significant at $95 \%$ confidence, which mirrors the trends in total EPS (Fig. 4A) over the same range. However, the difference in ALE production was nonsignificant once the

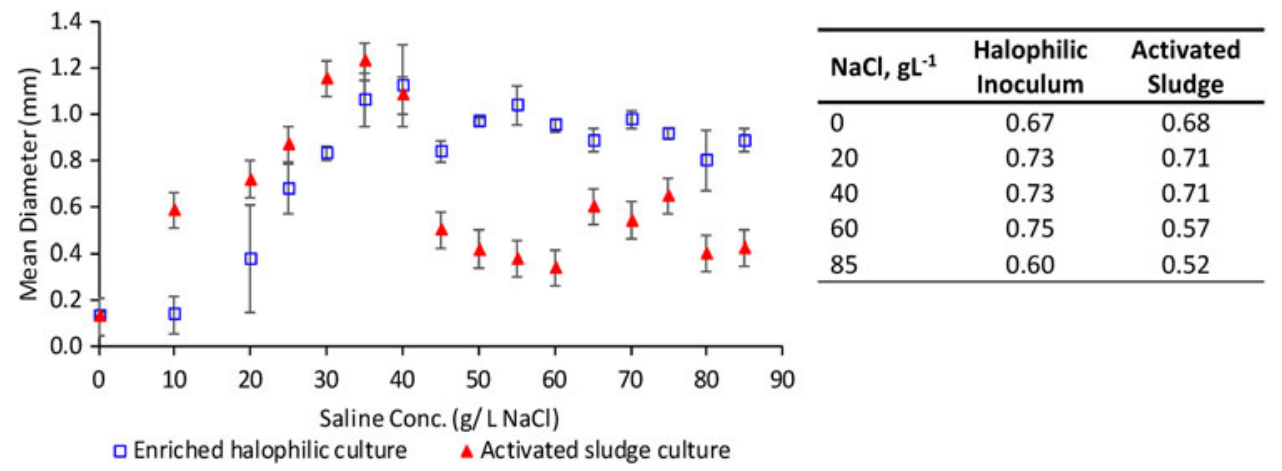

FIG. 2. Average granule sizes (left) and aspect ratios (right) for reactors inoculated with an enriched halophilic culture or activated sludge at increasing salt concentrations. 
FIG. 3. Enriched halophilic AGS at (A) $40 \mathrm{~g} / \mathrm{L} \mathrm{NaCl}$ and (B) $85 \mathrm{~g} / \mathrm{L}$ $\mathrm{NaCl}$; activated sludge AGS at (C) $40 \mathrm{~g} / \mathrm{L} \mathrm{NaCl}$ and (D) $85 \mathrm{~g} / \mathrm{L}$ $\mathrm{NaCl}$. AGS, aerobic granular sludge.
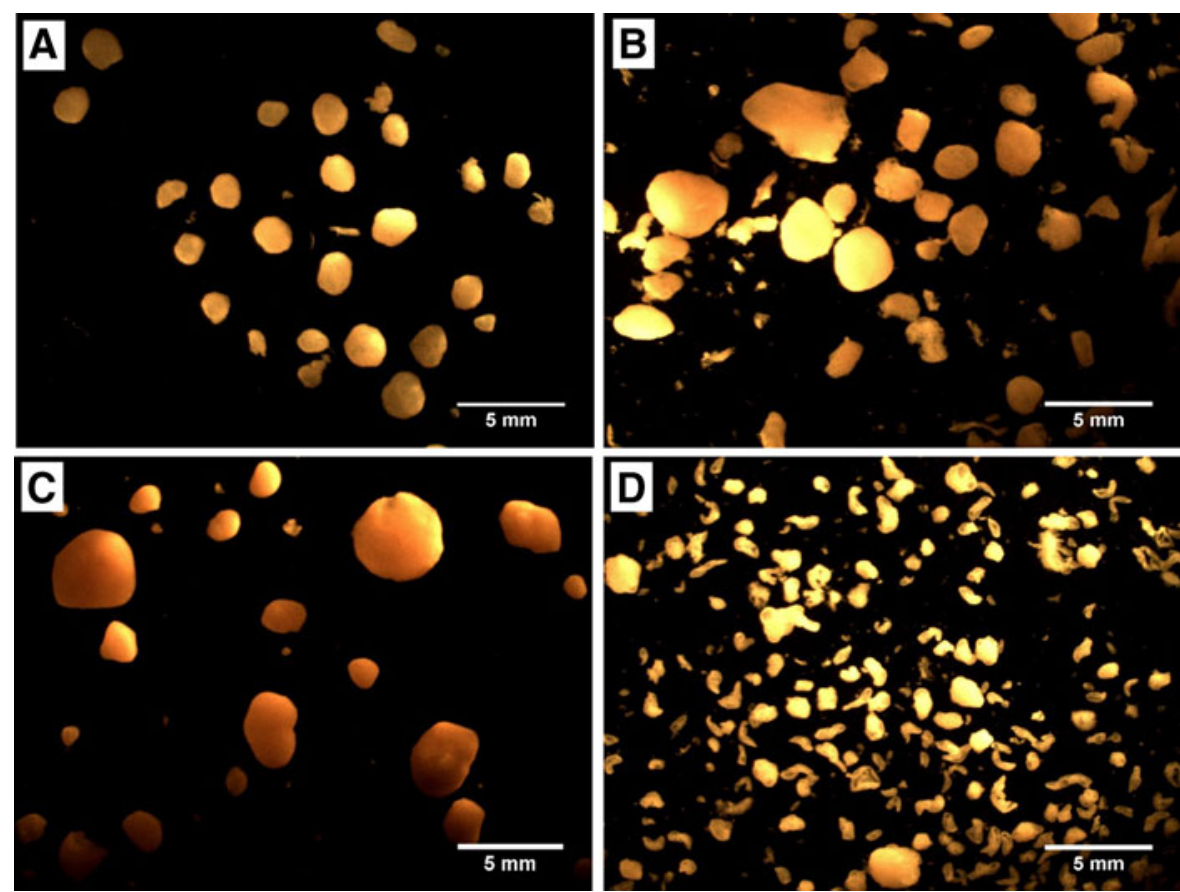

salinity increased to $85 \mathrm{~g} / \mathrm{L}$. Higher concentrations of EPS and ALE corresponded to the larger, and more consistent, granule sizes observed in the halophilic reactor under hypersaline conditions. Pearson's correlation analysis also showed that $\mathrm{SVI}_{5}$ values were positively correlated with
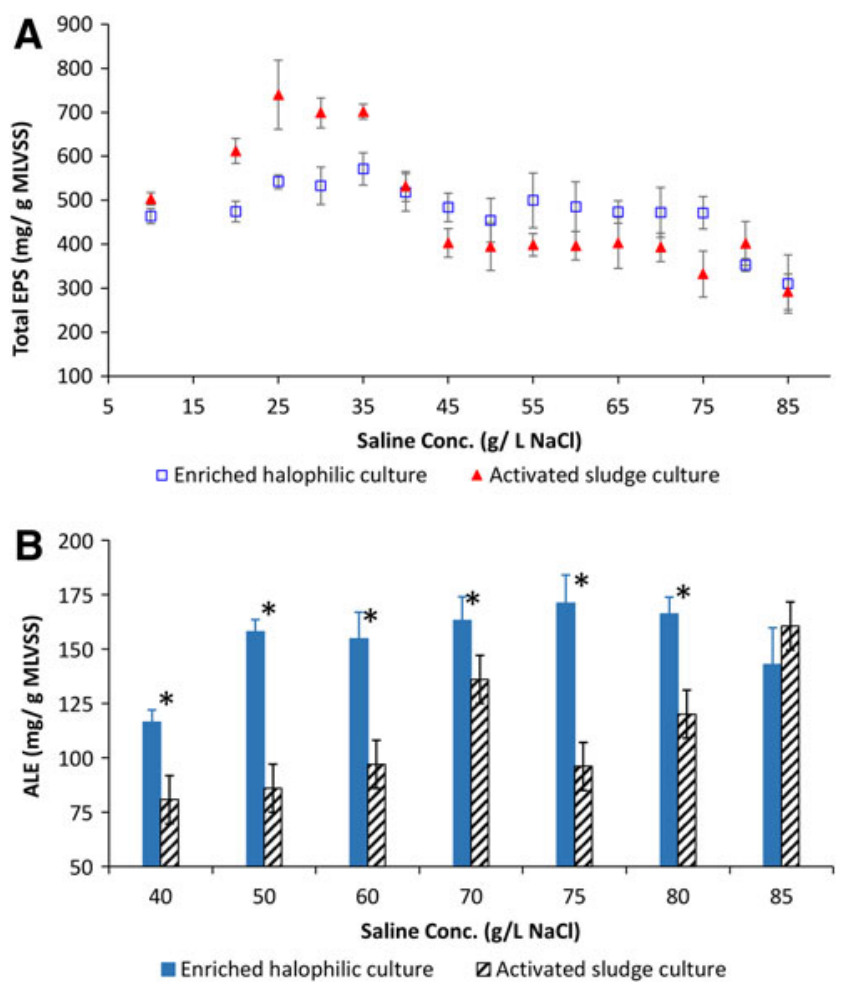

FIG. 4. (A) EPS production and (B) ALE production in reactors inoculated with an enriched halophilic culture or activated sludge. "**" Indicates a statistically significant difference $(p<0.05)$ in ALE production. EPS, extracellular polymeric substances; ALE, alginate-like exopolysaccharides.
ALE production in both cultures $(r=0.91, p=0.001$ for the enriched halophilic culture and $r=0.71, p=0.033$ for the activated sludge culture), further emphasizing the link between ALE production and granule structure.

The EPS cation content was dominated by $\mathrm{Na}^{+}$in both systems throughout the experiment, but there were notable differences in divalent cation concentrations based on both inoculant and total salinity (Fig. 5). Below $40 \mathrm{~g} / \mathrm{L} \mathrm{NaCl}$, both $\mathrm{Ca}^{2+}$ and $\mathrm{Mg}^{2+}$ were present at higher concentrations in EPS from the halophile-inoculated reactor, while the $\mathrm{Na}^{+}$
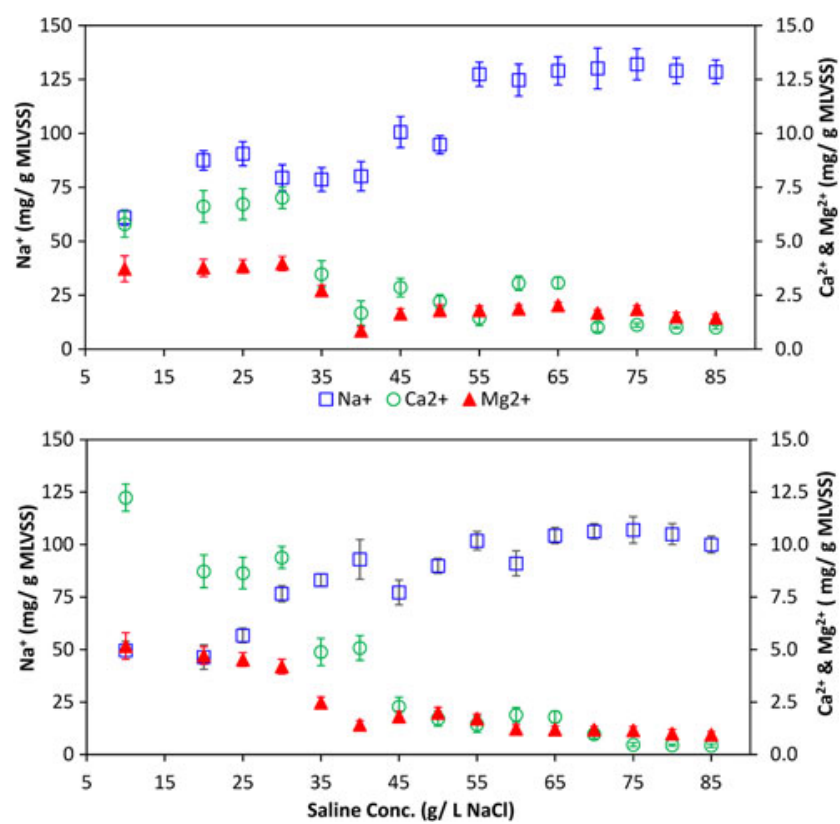

FIG. 5. Cation concentrations in the EPS of AGS formed from the activated sludge culture (top) and enriched halophilic culture (bottom). 
concentration was $25-30 \%$ lower. Above $40 \mathrm{~g} / \mathrm{L}$, divalent cation concentrations in EPS decreased to below $2 \mathrm{mg} / \mathrm{g}$ MLVSS in both reactors. While both reactors saw an increase in the sodium content of EPS under these same conditions, $\mathrm{Na}^{+}$ continued to be present at higher concentrations in the activated sludge reactor EPS, with a maximum concentration of $130 \mathrm{mg} \mathrm{Na}^{+} / \mathrm{g} \mathrm{MLVSS}$, compared with $100 \mathrm{mg} \mathrm{Na}^{+} / \mathrm{g}$ MLVSS, in the halophile-inoculated EPS. The differences in cation concentrations between the halophilic and activated sludge reactors were compared using a two-sample $t$-test, which showed significant differences at $95 \%$ confidence for $\mathrm{Ca}^{2+}$ and $\mathrm{Na}^{+}$( $p$ values of 0.035 and 0.00 , respectively), while $\mathrm{Mg}^{2+}$ was just above the threshold for significance at $95 \%$ confidence ( $p=0.057) . \mathrm{K}^{+}$followed a similar trend to the divalent cations in the enriched halophilic reactor, decreasing in the EPS as the bulk sodium concentration increased from 10 to $40 \mathrm{~g} / \mathrm{L} \mathrm{NaCl}$ (Supplementary Fig. S3). In the activated sludge reactor, EPSassociated $\mathrm{K}^{+}$was initially present at lower concentrations, but rose slightly as the bulk $\mathrm{Na}^{+}$concentration increased.

\section{Intracellular cations}

Intracellular calcium concentrations in the activated sludge reactor decreased with increasing addition of $\mathrm{NaCl}$ to the reactor, while intracellular $\mathrm{Na}^{+}$declined with increasing salinity from 45 to $60 \mathrm{~g} / \mathrm{L}$, and then recovered, reaching approximately the same concentration at $85 \mathrm{~g} / \mathrm{L} \mathrm{NaCl}$ as at $45 \mathrm{~g} / \mathrm{L}$ (Fig. 6). Intracellular calcium concentrations in the halophilic reactor were generally below $10 \mathrm{mg} / \mathrm{g}$ MLVSS at hypersaline conditions. Sodium concentrations were higher, averaging $46.8 \pm 3.7 \mathrm{mg} / \mathrm{g}$ MLVSS, but both $\mathrm{Ca}^{2+}$ and $\mathrm{Na}^{+}$ were unaffected by changes in salinity. At all salinities, intracellular $\mathrm{Ca}^{2+}$ and $\mathrm{Na}^{+}$concentrations in the halophilic reactor were substantially lower than corresponding values in the activated sludge reactor, pointing to a consistently different response to high external salt levels between the two microbial communities. Intracellular potassium concentrations were $35-40 \mathrm{mg} / \mathrm{g}$ MLVSS in both reactors and showed no consistent trend with increasing salinity (Supplementary Fig. S3).

\section{Microbial community structure}

At inoculation, the enriched halophilic culture comprised nine phyla across all samples; seven of these phyla contained relative abundances $>0.1 \%$ although two phyla, Proteo- bacteria and Firmicutes, were much more prevalent than the others (Fig. 7). The five most abundant genera in the enriched halophilic inoculum were Halomonas with a relative abundance of $59.2 \pm 9.2 \%$, followed by Staphylococcus $(39.5 \pm 11.3 \%)$, Planktosalinus $(0.5 \pm 0.1 \%)$, Corynebacterium $(0.4 \pm 0.1 \%)$, and Marinobacter $(0.1 \pm 0.05 \%)$, all of which are known to contain halophilic organisms (Supplementary Fig. S4). The activated sludge inoculum was much more diverse, comprising 37 phyla; 19 with relative abundances $>0.1 \%$. Proteobacteria, however, was the most abundant phylum in this inoculum as well. The five most abundant genera classified in the activated sludge culture were Thiothrix (with a relative abundance of $2.9 \pm 0.3 \%$ ), followed by Bdellovibrio $(2.7 \pm 0.1 \%)$, Planctomyces $(1.9 \pm 0.1 \%)$, Uncultured Xanthomonadaceae Family (1.7 $\pm 0.1 \%)$, and Hyphomicrobium (1.6 $\pm 0.1 \%$ ) (Supplementary Fig. S4). The

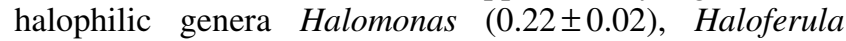
$(0.003 \pm 0.001)$, and Planktosalinus $(0.04 \pm 0.01)$ were also detected in the activated sludge inoculum, although at very low abundance levels.

The increase in salinity from 0 to $40 / \mathrm{L}$ in the activated sludge-inoculated reactor resulted in a microbial community shift favoring halophilic organisms. The resulting community structure of both reactors was relatively consistent across the hypersaline range of $40-85 \mathrm{~g} / \mathrm{L}$. At the phylum level, both reactors were dominated by Proteobacteria, followed by Bacteroidetes and then Actinobacteria (Fig. 7). At the genus level (Supplementary Fig. S4), Halomonas had a mean relative abundance of $23.2 \pm 2.1 \%$ across all tested salinities in the halophile-inoculated reactor. Halomonas was also selected as the most common genus in the activated sludgeinoculated reactor, with a final mean relative abundance of $25.2 \pm 6.1 \%$. Core microbiome analysis, which identifies the organisms that are present in at least $90 \%$ of the samples, showed that 14 taxa were responsible for $75 \%$ of the relative abundance in both systems between 40 and $85 \mathrm{~g} / \mathrm{L} \mathrm{NaCl}$ (Supplementary Fig. S5). Identifiable core genera in both reactors included Aequorivita, Azoarcus, Corynebacterium, Marinicella, Marinobacter, Nitratireductor, Pelagibacterium, Planktosalinus, Stappia, and Wenzhouxiangella, which are all known halophilic genera.

The convergence of bacterial communities between the two reactors represented a substantial decrease in the diversity from the activated sludge inoculum, but an increase in diversity for the halophile-inoculated system. Faith's

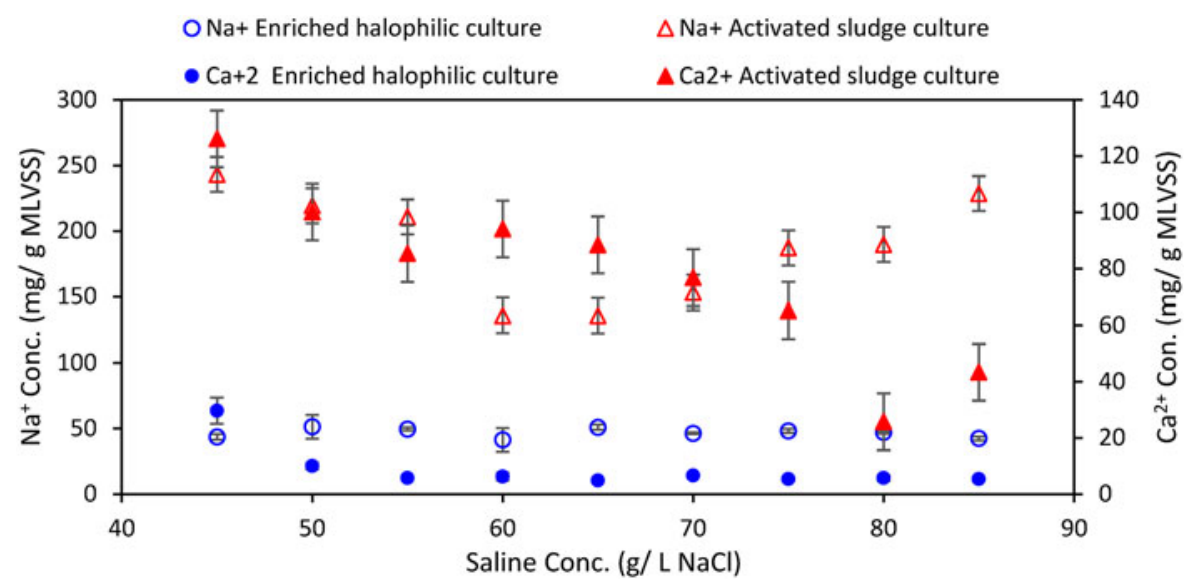

FIG. 6. Intracellular concentrations of calcium (filled symbols) and sodium (open symbols) in the halophilic and activated sludge reactors under hypersaline conditions. 


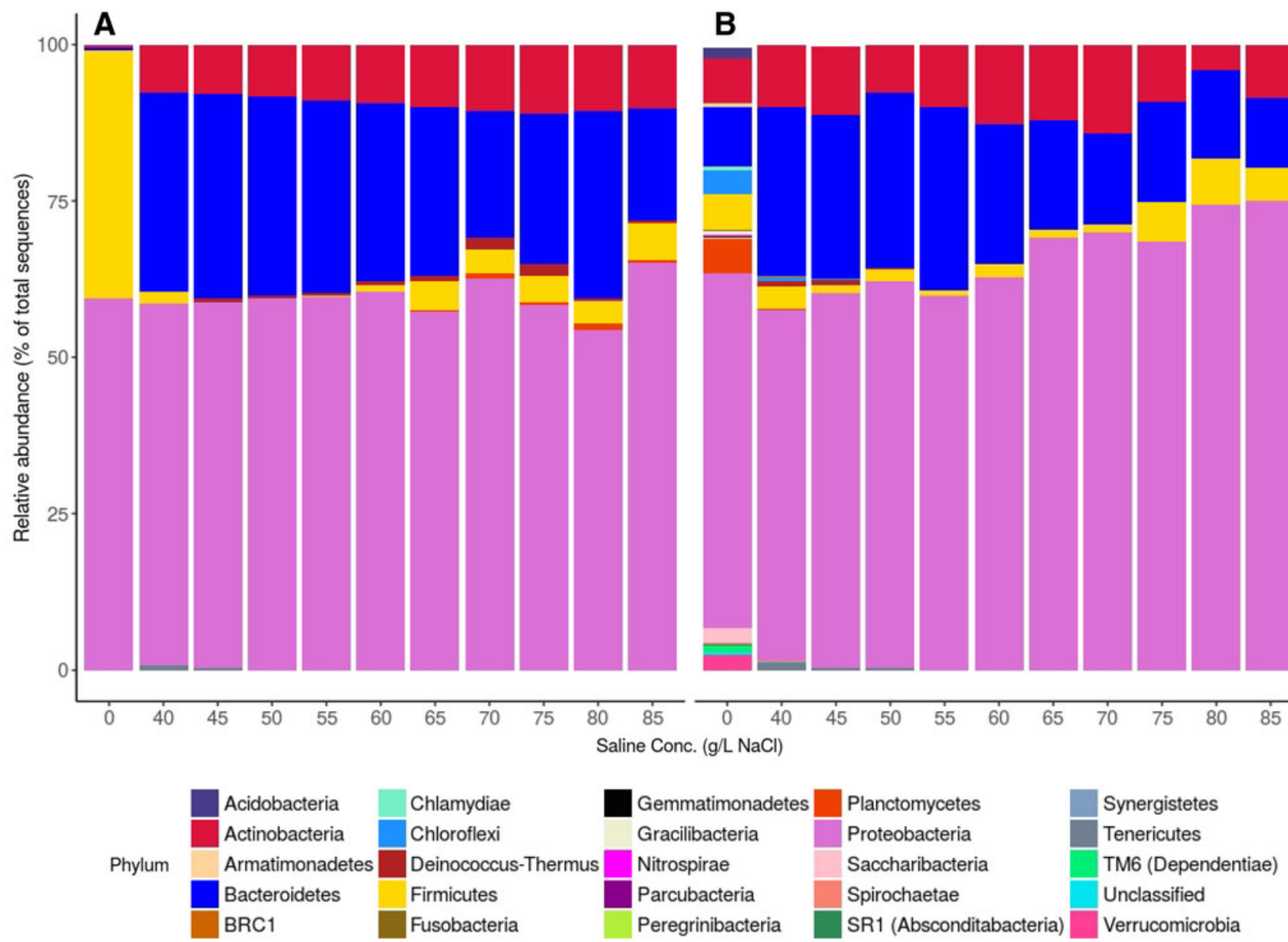

FIG. 7. Stacked bar plot showing taxa with relative abundance $\geq 0.1 \%$ at phylum level for inoculum $(0 \mathrm{~g} / \mathrm{L} \mathrm{NaCl})$ and at each saline concentration for (A) the reactor inoculated with an enriched halophilic culture and (B) the reactor inoculated with activated sludge.

phylogenetic diversity analysis (Supplementary Fig. S6) revealed that the activated sludge inoculum diversity, at $76.4 \pm 4.8$, was significantly higher than the enriched halophilic culture inoculum value of $2.6 \pm 1.7(p<0.05)$. At $40 \mathrm{~g} /$ $\mathrm{L}$, the activated sludge reactor was significantly less diverse with a Faith's diversity index of $17.9 \pm 5.7$, while the diversity index in the halophile-inoculated reactor increased to $7.8 \pm 0.2$. By $45 \mathrm{~g} / \mathrm{L}$, the activated sludge reactor had a diversity index of $8.3 \pm 1.0$, and the halophile-inoculated reactor had a diversity index of $10.3 \pm 0.5$. No significant change in richness was observed in either reactor as salinity increased beyond this point.

\section{Discussion}

Despite the observed similarity in community structure, only the halophile-inoculated reactor was able to retain larger granules at hypersaline conditions ( $\geq 40 \mathrm{~g} \mathrm{NaCl} / \mathrm{L})$. Several previous studies have shown that AGS formation using organisms from domestic wastewater decreases as the salinity increases above 15-30 g NaCl/L (Pronk et al., 2014; Corsino et al., 2017; Wang et al., 2017a), which is consistent with results reported here for the activated sludge reactor from 40 to $70 \mathrm{~g} / \mathrm{L} \mathrm{NaCl}$. The maintenance of stable granules in the halophile-amended reactor at up to $85 \mathrm{~g} / \mathrm{L} \mathrm{NaCl}$, by contrast, represents a higher level of salinity tolerance than was observed in most previous studies. Ou et al. (2018) were also able to maintain stable granules up to $9 \%$ salinity, and noted that their system was also dominated by moderate halophiles. Overall, there was a strong correlation between EPS and granule size in both reactors $(p<0.05)$. This finding is in agreement with previous studies (McSwain et al., 2005; Ramos et al., 2015; Corsino et al., 2017; Wang et al., 2017a, 2017b) that emphasize the role of EPS in AGS formation. Secretion of EPS protects embedded microorganisms from external shocks (Xu et al., 2020). Halophilic organisms may be more capable of maintaining EPS production even in the face of increased bulk salinity, thus producing the more stable granules observed in the halophile-amended reactor at hypersaline conditions.

ALE can also play a crucial role in maintaining AGS structure due to the presence of a polysaccharide network that maintains AGS elasticity and high affinity to cations, which strengthen the AGS structure (Lin et al., 2010; Li et al., 2017; Pishgar et al., 2020). ALE production in the enriched halophilic culture was consistently higher over the salinity range of 40-80 $\mathrm{g} \mathrm{NaCl} / \mathrm{L}$. Statistical analysis showed that this difference was statistically significant at $95 \%$ confidence. Other 
studies have reported that increased ALE production with high salinity may help cope with high osmotic pressure and sodium toxicity (Wan et al., 2014; Meng et al., 2019). The higher concentrations of ALE present in the halophilic reactor may therefore be another sign that these organisms are better able to adapt to salt stress in ways that maintain granule integrity. It is interesting to note that, at $85 \mathrm{~g} / \mathrm{L} \mathrm{NaCl}$, where MLVSS concentrations increase significantly in the activated sludge reactor, ALE production in the two reactors was not statistically different.

The three dominant phyla present in both reactors at hypersaline conditions (Proteobacteria, Bacteroidetes, and Actinobacteria) are identical to those reported by Huang et al. (2019) for an SBR operated at $30 \mathrm{~g} / \mathrm{L} \mathrm{NaCl}$, although the current study also has Firmicutes present (at lower abundance) in both reactors. This finding is also in agreement with previous studies that reported Proteobacteria as one of the bacterial lineages in a marine biocommunity (Zhang et al., 2016; Ou et al., 2018). In addition, ALE production was correlated with Proteobacteria in both reactors. These results strongly suggest that microbes in the phylum Proteobacteria are an important component to halophilic granule formation, possibly as a major contributor to ALE production. However, the current study also found a negative correlation between Proteobacteria and total EPS production in both reactors.

Pearson's correlation analysis further showed that there was a negative correlation between ALE and phylum Bacteroidetes in both reactors. Thomas et al. (2011) observed that organisms in the phylum Bacteroidetes were the main contributor to polysaccharides and protein degradation, while Zhang et al. (2016) reported that this phylum played a main role in the biodegradation of organic matter. There was also a negative correlation between salt content above $60 \mathrm{~g} / \mathrm{L} \mathrm{NaCl}$ and $\mathrm{Bac}-$ teroidetes. This finding indicates that granule structure could benefit at higher salinities from Bacteroidetes inhibition resulting in higher ALE content. However, Bacteroidetes had a positive correlation with total EPS production. As with the similar (but opposite) correlations between Proteobacteria, ALE, and EPS, these results suggest a complicated relationship between the microbial community composition and granule stability. Statistical analysis of community results at the genus level did not produce any significant correlations to EPS or ALE production in either reactor. While it is possible that granule integrity may be linked to the presence of individual halophilic species, rather than the presence of halophiles more generally, such an analysis is beyond the scope of this work.

Relatively few previous studies have reported $\mathrm{Na}^{+}$concentrations in the EPS matrix under high-salinity conditions. Both Kara et al. (2008) and Fang et al. (2018) reported that sodium concentrations in the sludge matrix increased with increasing concentration in the wastewater. Kara et al. (2008) measured $\mathrm{Na}^{+}$concentrations of $23-115 \mathrm{mg} / \mathrm{g}$ sludge as the bulk $\mathrm{NaCl}$ content increased from 10 to $460 \mathrm{mg} / \mathrm{L}$. Despite the higher bulk salt concentrations, the current values for the activated sludge reactor are similar (13-130 mg/g sludge), but higher in the halophilic reactor (19-425 mg/g sludge), particularly under hypersaline conditions. Fang et al. (2018) reported accumulation of $100 \mathrm{mg} \mathrm{Na}^{+} / \mathrm{g}$ EPS at bulk $\mathrm{NaCl}$ concentrations of $30 \mathrm{~g} / \mathrm{L}$. Normalizing the $\mathrm{Na}^{+}$concentrations reported in Fig. 5 to EPS production by dividing by total EPS concentration (Fig. 4A) shows that $\mathrm{Na}^{+}$accumulation in the EPS was higher in both reactors in the current study, with 322 and $440 \mathrm{mg} \mathrm{Na}^{+} / \mathrm{g}$ EPS in the activated sludge and halophilic reactors, respectively, at $85 \mathrm{~g} / \mathrm{L} \mathrm{NaCl}$. As the solution $\mathrm{NaCl}$ concentration increased from 10 to $85 \mathrm{~g} / \mathrm{L}$ in the current study, $\mathrm{Na}^{+}$concentrations in the EPS approximately doubled in both reactors (Fig. 5), which suggests that there may be a maximum capacity of the EPS for cation accumulation. However, this experiment did not observe a correlation between sodium substitution for divalent cations in the EPS and granule integrity. The decrease in $\mathrm{Ca}^{2+}$ and $\mathrm{Mg}^{2+}$ EPS concentrations in the activated sludge reactor began well before the salinity $(40 \mathrm{~g} /$ L) where granule size began to decay. In addition, the halophilic reactor showed the same trends with respect to divalent cation concentration, but without the decrease in granule size. Thus, there is no indication that divalent cation replacement by $\mathrm{Na}^{+}$necessarily leads to AGS fragmentation.

The halophilic reactor did accumulate less intracellular $\mathrm{Na}^{+}$and $\mathrm{Ca}^{2+}$ under hypersaline conditions. Individual organisms within the granule structure may address increased osmotic pressure caused by high salinity through selective accumulation of intracellular cations $\left(\mathrm{Ca}^{2+}, \mathrm{Mg}^{2+}, \mathrm{Na}^{+}\right.$, and $\mathrm{K}^{+}$) (Hänelt and Müller, 2013; Wan et al., 2014). Wang et al. (2017a) also observed an increase in $\mathrm{K}^{+}$concentration in granules and a corresponding decrease in $\mathrm{Na}^{+}$, attributed to the actions of $\mathrm{K}^{+} / \mathrm{Na}^{+}$and $\mathrm{Na}^{+} / \mathrm{H}^{+}$pumps. In the current study, however, no increase was observed in intracellular $\mathrm{K}^{+}$ with higher salinity. Wan et al. (2014) reported that intracellular $\mathrm{Ca}^{2+}$ can be regulated by $\mathrm{Na}^{+} / \mathrm{Ca}^{2+}$ membrane exchange. However, the current study did not address whether better exclusion of sodium from the cells is due to an active response to the high-salinity conditions, or a function of existing differences in microbial populations between the two reactors. Either way, this result provides an avenue for further exploration in assessing how granule structures adapt to highsalinity wastewater environments.

\section{Summary}

Community analysis showed that the population of both reactors converged toward a halophile-dominated system, but the differences in granule size and integrity indicate a positive effect of inoculating with halophilic organisms. Most notably, bioaugmentation with halophilic organisms resulted in much less sensitivity of EPS and ALE production to salinity, particularly at hypersaline conditions. In addition, intracellular cation concentrations were much lower in the halophile-amended system throughout the hypersaline range. Sodium substitution for divalent cations in the EPS, by contrast, occurred to a similar extent in both reactors and did not correspond to changes in granule integrity.

\section{Author Disclosure Statement}

No competing financial interests exist.

\section{Funding Information}

This work was supported by the National Science Foundation (Grant Numbers OIA-1632892 and CBET-1512667), the University of Kansas Strategic Initiative Program, and the Iraqi Ministry of Higher Education and Scientific Research (MOHESR) government grant program. 


\section{Supplementary Material}

Supplementary Data

Supplementary Figure S1

Supplementary Figure S2

Supplementary Figure S3

Supplementary Figure S4

Supplementary Figure S5

Supplementary Figure S6

Supplementary Table S1

\section{References}

Abou-Elela, S.I., Kamel, M.M., and Fawzy, M.E. (2010). Biological treatment of saline wastewater using a salt-tolerant microorganism. Desalination 250, 1.

APHA. (2005). Standard Methods for the Examination of Water and Wastewater, 21 ed. Washington, DC: American Public Health Association.

Bassin, J.P., Pronk, M., Muyzer, G., Kleerebezem, R., Dezotti, M., and van Loosdrecht, M.C.M. (2011). Effect of elevated salt concentrations on the aerobic granular sludge process: Linking microbial activity with microbial community structure. Appl. Environ. Microbiol. 77, 7942.

Capodici, M., Bella, G.D., Nicosia, S., and Torregrossa, M. (2015). Effect of chemical and biological surfactants on activated sludge of MBR system: Microscopic analysis and foam test. Bioresour. Technol. 177, 80.

Caporaso, J.G., Kuczynski, J., Stombaugh, J., Bittinger, K., Bushman, F.D., Costello, E.K., Fierer, N., Peña, A.G., Goodrich, J.K., Gordon, J.I., Huttley, G.A., Kelley, S.T., Knights, D., Koenig, J.E., Ley, R.E., Lozupone, C.A., McDonald, D., Muegge, B.D., Pirrung, M., Reeder, J., Sevinsky, J.R., Turnbaugh, P.J., Walters, W.A., Widmann, J., Yatsunenko, T., Zaneveld, J., and Knight, R. (2010). QIIME allows analysis of high-throughput community sequencing data. Nat. Methods 7, 335.

Caporaso, J.G., Lauberb, C.L., Walters, W.A., Berg-Lyons, D., Lozupone, C.A., Turnbaugh, P.J., Fierer, N., and Knight, R. (2011). Global patterns of 16S rRNA diversity at a depth of millions of sequences per sample. Proc Natl Acad Sci U S A. 108, 4516.

Castillo-Carvajal, L.C., Sanz-Martin, J.L., and BarraganHuerta, B.E. (2014). Biodegradation of organic pollutants in saline wastewater by halophilic microorganisms: A review. Environ. Sci. Pollut. Res. 21, 9578.

Corsino, S.F., Campo, R., Di Bella, G., Torregrossa, M., and Viviani, G. (2018). Aerobic granular sludge treating shipboard slop: Analysis of total petroleum hydrocarbons loading rates on performacnes and stability. Process Biochem. 65, 164.

Corsino, S.F., Capodici, M., Torregrossa, M., and Viviani, G. (2017). Physical properties and extracellular polymeric substances pattern of aerobic granular sludge treating hypersaline wastewater. Bioresour. Technol. 229, 152.

Cui, Y.W., Zhang, H.Y., Ding, J.R., and Peng, Y.Z. (2016). The effects of salinity on nitrification using halophilic nitrifiers in a sequencing batch reactor treating hypersaline wastewater. Sci. Rep. 6, 24825.

Deng, S., Wang, L., and Su, H. (2016). Role and influence of extracellular polymeric substances on the preparation of aerobic granular sludge. J. Environ. Manage. 173, 49.

Dubois, M., Gilles, K.A., Hamilton, J.K., Rebers, P.A., and Smith, F. (1956). Colorimetric method for determination of sugars and related substances. Anal. Chem. 28, 350.
Fakhru'l-Razi, A., Pendashteh, A., Abdullah, L.C., Biak, D.R.A., Madaeni, S.S., and Abidin, Z.Z. (2009). Review of technologies for oil and gas produced water treatment. J. Hazard. Mater. 170, 530.

Fang, F., Yang, M.-M., Wang, H., Yan, P., Chen, Y.-P., and Guo, J.-S. (2018). Effect of high salinity in wastewater on surface properties of anammox granular sludge. Chemosphere 210, 366.

Felz, S., Al-Zuhairy, S., Aarstad, O.A., van Loosdrecht, M.C.M., and Lin, Y.M. (2016). Extraction of structural extracellular polymeric substances from aerobic granular sludge. J. Vis. Exp. 115, 54534.

Gao, D., Liu, L., Laing, H., and Wu, W.-M. (2011). Aerobic granular sludge: Characterization, mechanism of granulation and application to wastewater treatment. Crit. Rev. Biotechnol. 31, 137.

Hänelt, I., and Müller, V. (2013). Molecular mechanisms of adaptation of the moderately halophilic bacterium Halobacillis halophilus to its environment. Life 3, 234.

Higgins, M., and Novak, J. (1997). The effect of cations on the settling and dewatering of activated sludges: Laboratory results. Water Environ. Res. 69, 215.

Huang, J.L., Wang, H.H., Alam, F., and Cui, Y.W. (2019). Granulation of halophilic sludge inoculated with estuarine sediments for saline wastewater treatment. Sci. Total Environ. $682,532$.

Ismail, S.B., de La Parra, C.J., Temmink, H., and van Lier, J.B. (2010). Extracellular polymeric substances (EPS) in upflow anaerobic sludge blanket (UASB) reactors operated under high salinity conditions. Water Res. 44, 1909.

Kara, F., Gurakan, G., and Sanin, F. (2008). Monovalent cations and their influence on activated sludge floc chemistry, structure, and physical characteristics. Biotechnol. Bioeng. 100, 231.

Lefebvre, O., and Moletta, R. (2006). Treatment of organic pollution in industrial saline waastewater: A literature review. Water Res. 40, 3671

Li, X., Luo, J., Guo, G., Mackey, H.R., Hao, T., and Chen, G. (2017). Seawater-based wastewater accelerates development of aerobic granular sludge: A laboratory proof-of-concept. Water Res. 115, 210.

Li, X.Y., and Yang, S.F. (2007). Influence of loosely bound extracellular polymeric substances (EPS) on the flocculation, sedimentation and dewaterability of activated sludge. Water Res. 41, 1022.

Lin, Y., Kreuk, M.D., van Loosdrecht, M.C.M., and Adin, A. (2010). Characterization of alginate-like exopolysaccharides isolated from aerobic granular sludge in pilot-plant. Water Res. 44, 3355.

Lin, Y.M., Sharma, P.K., and van Loosdrecht, M.C.M. (2013). The chemical and mechanical differences between alginatelike exopolysaccharides isolated from aerobic flocculent sludge and aerobic granular sludge. Water Res. 47, 57.

McSwain, B.S., Irvine, R.L., Hausner, M., and Wilderer, P.A. (2005). Composition and distribution of extracellular polymeric substances in aerobic flocs and granular sludge. Appl. Environ. Microbiol. 71, 1051.

Meng, F.S., Liu, D.F., Pan, Y.W., Xi, L.M., Yang, D., and Huang, W.L. (2019). Enhanced amount and quality of alginate-like exopolysaccharides in aerobic granular sludge for the treatment of salty wastewater. Bioresources 14, 139.

Ou, D., Li, H., Li, W., Wu, X., Wang, Y.-Q., and Liu, Y-D. (2018). Salt-tolerance aerobic granular sludge: Formation and microbial community characteristics. Bioresour. Technol. $249,132$. 
Özsoy, G. (2006). An Investigation of Agricultural Use Potential of Wastewater Sludges in Turkey with Respect to Heavy Metals and Pathogens (Thesis). The Graduate School of Natural and Applied Sciences, Middle East Technical University, Ankara, Turkey, pp. 149.

Pendashteh, A.R., Abdullah, L.C., Fakhru'l-Razi, A., Madaeni, S.S., Abidin, Z.Z., and Biak, D.R.A. (2012). Evaluation of membrane bioreactor for hypersaline oily wastewater treatment. Process Saf. Environ. Prot. 90, 45.

Pishgar, R., Dominic, J.A., Tay, J.H., and Chu, A. (2020). Pilotscale investigation on nutrient removal characteristics of mineral-rich aerobic granular sludge: Identification of uncommon mechanisms. Water Res. 168, 115151.

Pronk, M., Bassin, J.P., Kreuk, M.K.D, Kleerebezem, R., and van Loosdrecht, M.C.M. (2014). Evaluating the main and side effects of high salinity on aerobic granular sludge. Appl. Microbiol. Biotechnol. 98, 1339.

Ramos, C., Suárez-Ojeda, M.E., and Carrera, J. (2015). Longterm impact of salinity on the performance and microbial population of an aerobic granular reactor treating a highstrength aromatic wastewater. Bioresour. Technol. 198, 844.

Salminikhas, N., Tizaghadam, M., and Rashidi Mehrabadi, A. (2016). Treatment of saline municipal wastewater using hydrid growth system. J. Biol. Eng. 10, 9.

Sharghi, E.A., Bonakdarpour, B., and Pakzadeh, M. (2014). Treatment of hypersaline produced water employing a moderately halophilic bacterial consortium in a membrane bioreactor: Effect of salt concentration on organic removal performance, mixed liquor characteristics and membrane fouling. Bioresour. Technol. 164, 203.
Taheri, E., Hajian, M.H.K., Amin, M.M., Nikaeen, M., and Hassanzadeh, A. (2012). Treatment of saline wastewater by a sequencing batch reactor with emphasis on aerobic granule formation. Bioresour. Technol. 111, 21.

Thomas, F., Hehemann, J.H., Rebuffet, E., Czjzek, M., and Michel, G. (2011). Environmental and gut bacteroidetes: The food connection. Front. Microbiol. 2, 93.

Vyrides, I., and Stuckey, D.C. (2009). A modified method for the determination of chemical oxygen demand (COD) for samples with high salinity and low organics. Bioresour. Technol. 100, 979.

Wan, C., Yang, X., Lee, D.-J., Liu, X., Sun, S., and Chen, C. (2014). Partial nitrification of wastewaters with high $\mathrm{NaCl}$ concentrations by aerobic granules in continuous-flow reactor. Bioresour. Technol. 152, 1.

Wang, X., Yang, T., Lin, B., and Tang, Y. (2017a). Effects of salinity on the performance, microbial community, and functional proteins in an aerobic granular sludge system. Chemosphere. 184, 1241.

Wang, Z., van Loosdrecht, M.C.M., and Saikaly, P.E. (2017b). Gradual adaptation to salt and dissolved oxygen: Strategies to minimize adverse effect of salinity on aerobic granular sludge. Water Res. 124, 702.

Xu, J., Pang, H., He, J., Nan, J., Wang, M., and Li, L. (2020). Start-up of aerobic granular biofilm at low temperature: Performance and microbial community dynamics. Sci. Total Environ. 698, 134311.

Zhang, Y., Li, B., Xu, R.-X., Wang, G.-X., Zhou, Y., and Xie, B. (2016). Effects of pressurized aeration on organic degradation efficiency and bacterial community structure of activated sludge treating saline wastewater. Bioresour. Technol. 222, 182. 